\title{
Robotic Arm Using Servo Motor and Arduino Uno Controlled with Potentiometer
}

\author{
Shulhan ${ }^{1}$, Farhan Astwensa ${ }^{1}$, Fikrie Reza Fauzan ${ }^{1}$, and Iksan Bukhori ${ }^{1 *}$ \\ ${ }^{1}$ Study Program of Electrical Engineering, President University, Bekasi 17550, Indonesia \\ *Corresponding author: iksan.bukhori@president.ac.id
}

\begin{abstract}
Robotic arm has been widely used in many applications, especially in industry. With this kind of advancement, the needs to introduce this technology to students at early age has increased. However, many students still consider this kind of technology as something out of reach. This project aims to create a very simple robotic arm using servo motor and materials which can be easily obtained around the household. The resulting robot is also programmable and electronically movable, thus enabling more freedom of how to move it. This in turn create a good introductory tool for the students to learn about the structure and motion of robotic arm.
\end{abstract}

Keywords: Arduino, Potentiometer, Robotic Arm, Servo

\section{INTRODUCTION}

An automated arm, at times alluded to as a modern robot, is regularly depicted as a 'mechanical' arm. It is a gadget that works likewise to a human arm, with various joints that either move along a pivot or can turn in specific ways. Actually, some mechanical arms are human and attempt to copy the definite developments of human arms. They are, much of the time programmable and used to perform explicit assignments, most regularly for assembling, manufacture, and modern applications. They can be little gadgets that perform perplexing, nitty gritty undertakings, sufficiently little to be held in one hand; or so enormous that their compass is sufficiently huge to develop whole structures [1].

Automated arms were initially intended to aid large scale manufacturing processing plants, most broadly in the assembling of vehicles. They were additionally actualized to alleviate the danger of damage for laborers, and to embrace dreary undertakings, in order to free specialists to focus on the more perplexing components of creation. These early mechanical arms were for the most part utilized to embrace basic, dreary welding errands. As innovations create, specifically automated vision and sensor innovation, the job of mechanical arms is evolving. This article gives a concise outline of Automated Arms in assembling [2].

\section{BASIC THEORY}

\section{A. Servo Motor}

Servo motor is an electrical tool that may push or rotate an object with incredible precision. If you want to rotate and object at some specific angles or distance, then you definitely use servo motor. It is simply made up of easy motor which run via servo mechanism. If motor is used is DC powered then it's far referred to as DC servo motor, and if it is AC powered motor then its miles referred to as AC servo motor. We can get a very excessive torque servo motor in a small and light weight packages. Due to these features, they're being utilized in any applications like toy car, RC helicopters and planes, Robotics, Machine etc. One of the servomotors us ed in the production phase of the project is shown in Fig. 1.

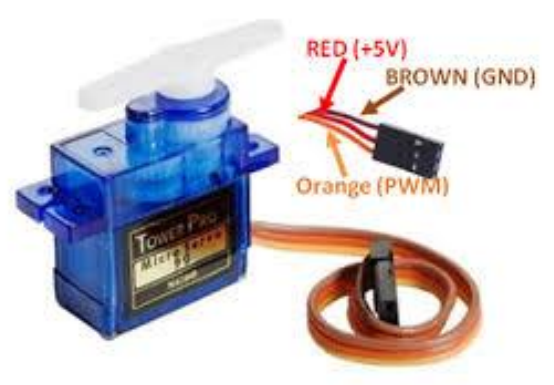

Figure 1. DC Servo Motor [3]

Servo engines are appraised in $\mathrm{kg} / \mathrm{cm}$ (kilogram per centimeter) most diversion servo engines are evaluated at 3 $\mathrm{kg} / \mathrm{cm}$ or $6 \mathrm{~kg} / \mathrm{cm}$ or $12 \mathrm{~kg} / \mathrm{cm}$. This $\mathrm{kg} / \mathrm{cm}$ discloses to you how much weight your servo engine can lift at a specific separation. For instance, A $6 \mathrm{~kg} / \mathrm{cm}$ Servo engine ought to have the option to lift $6 \mathrm{~kg}$ if the heap is suspended $1 \mathrm{~cm}$ away from the engines shaft, the more prominent the separation the lesser the weight conveying limit. The situation of a servo engine is chosen by electrical heartbeat and its hardware is set next to the engine. 


\section{B. Potentiometer}

A potentiometer (otherwise called a pot or potmeter) is characterized as a 3-terminal variable resistor where the obstruction is physically differed to control the progression of electric flow. Potentiometers can be used as voltage dividers. To use the potentiometer as a voltage divider, all the three pins are connected. One of the outer pins is connected to the GND, the other to Vcc and the middle pin is the voltage output. Fig. 2 shows the pins description.

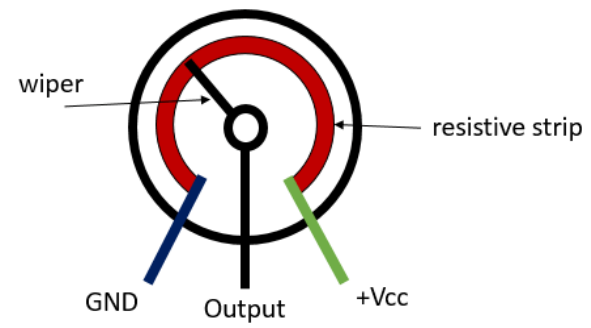

Figure 2. Potentiometer description

When the potentiometer is used as a voltage divider, the wiper position determines the output voltage. The circuit diagram is shown in Fig. 3.
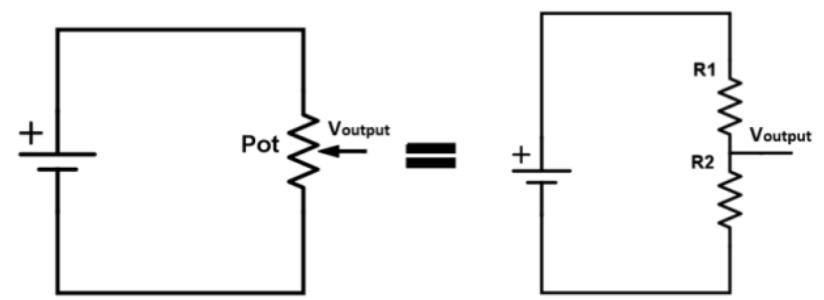

Figure 3. Potentiometer Circuit Diagram

The output voltage can be calculated using the Eq (1) obtained from Ohm's Law.

$$
V_{\text {out }}=V_{c c} \times \frac{R_{2}}{R_{1+} R_{2}}
$$

\section{Arduino Uno}

The Arduino Uno is a microcontroller board dependent on the ATmega328. It has 14 computerized input/yield pins (of which 6 can be utilized as PWM yields), 6 simple information sources, a $16 \mathrm{MHz}$ precious stone oscillator, a USB association, a power jack, an ICSP header, and a reset catch. It contains everything expected to help the microcontroller; just interface it to a PC with a USB link or power it with an air conditioner to DC connector or battery to begin. The Uno varies from every single going before board in that it doesn't utilize the FTDI USB-to-sequential driver chip. Rather, it includes the ATmega8U2 modified as a USB-to-sequential converter. "Uno" signifies one in Italian and is named to stamp the up-and-coming arrival of Arduino 1.0. The Uno and rendition 1.0 will be the reference forms of Arduino, pushing ahead. The appearance of Arduino Uno board is shown in Fig. 4.

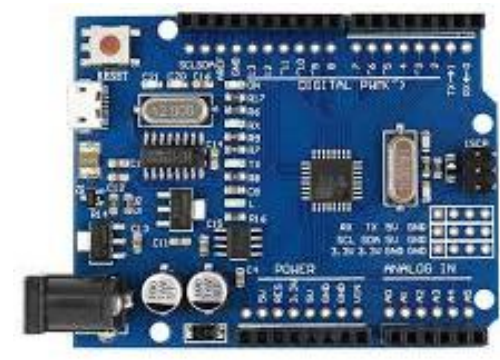

Figure 4. Arduino Uno

The Uno is the most recent in a progression of USB Arduino sheets, and the reference model for the Arduino stage; or an examination with past forms, see the file of Arduino sheets. Table 1 shows the specification of Arduino Uno.

Table 1. Arduino Specification

\begin{tabular}{|c|c|}
\hline Parameter & Value \\
\hline Microcontroller & ATmega28 \\
\hline Operating voltage & $5 \mathrm{v}$ \\
\hline Input voltage & $7-12 \mathrm{v}$ \\
\hline Digital I/O Pins & 14 \\
\hline Analog input pins & 6 \\
\hline DC current per I/O & $40 \mathrm{~mA}$ \\
\hline DC current for 3-3v pin & $50 \mathrm{~mA}$ \\
\hline Flash memory & $32 \mathrm{~kb}$ \\
\hline Clock speed & $16 \mathrm{MHz}$ \\
\hline
\end{tabular}

\section{CharaCteristic OF Robotic ARM}

Kinematics in robotics is the science of motion investigation. Robot arm links can be rotated or offset according to the reference coordinate frame. A systematic and general approach developed by Denavit and Hartenberg establishes the relationship between the robot endpoint and the total displacement of robot arm links. Angular and linear displacements between limbs are called joint coordinates and are defined by limb variables. In order to determine the amount of rotation and displacement according to the reference coordinate system of the endpoint, the matrices A which represent the amounts of each limb rotation and displacement are multiplied in turn. If the coordinates of the end point are given, limb variables can be obtained by going backward. These operations are called forward and inverse kinematics.

\section{A. Motor Servo Controlled by Potentiometer}

Robotic arm is controlled with potentiometer, by reducing or increasing the values of potentiometer itself. For potentiometer itself has values from 0 until 1028. And as we discussed before potentiometer is controlling the voltage. By making the potentiometer as voltage divider we could control the values of servo which is the values from 0 until 180. But in here we put different of values of each servo motor, sometime the maximum for the values of the servo motor is 120,90 and etc. It depends on your choices. But we have to consider that the servo values are only from 0 up to 180 [4], [5].

\section{B. Motor Servo Controlled by App Inventor}

We have another alternative way to control the servo motor which is controlled by app. But we need some extra 
item which is Bluetooth HC-05. To make the app we could use MIT Inventor application. we have a lot of option to control the servo, for the instance we could use joystick.

\section{DESIGN IMPLEMENTATION}

\section{A. Circuit Design Description}

To design the circuit, we use VBB application to make the circuit of the robotic arm as seen in Fig. 5.

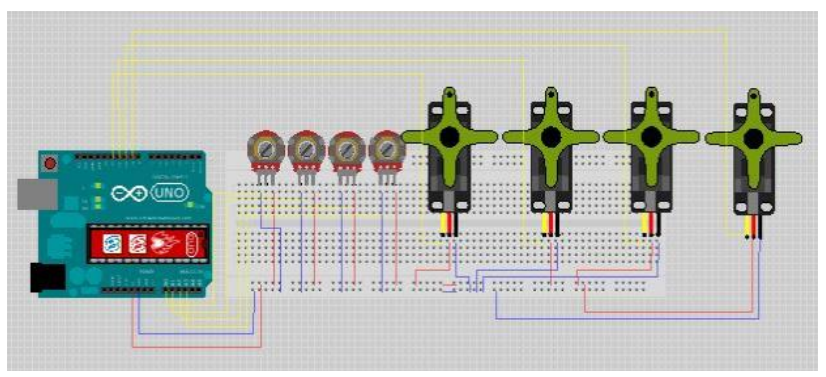

Figure 5. Circuit Description

\section{B. Body Design}

There are 5 parts of the body robotic arm. There are shoulder, elbow, wrist, claw, and potentiometer controller. The configuration of these five parts is shown in Fig. 6.

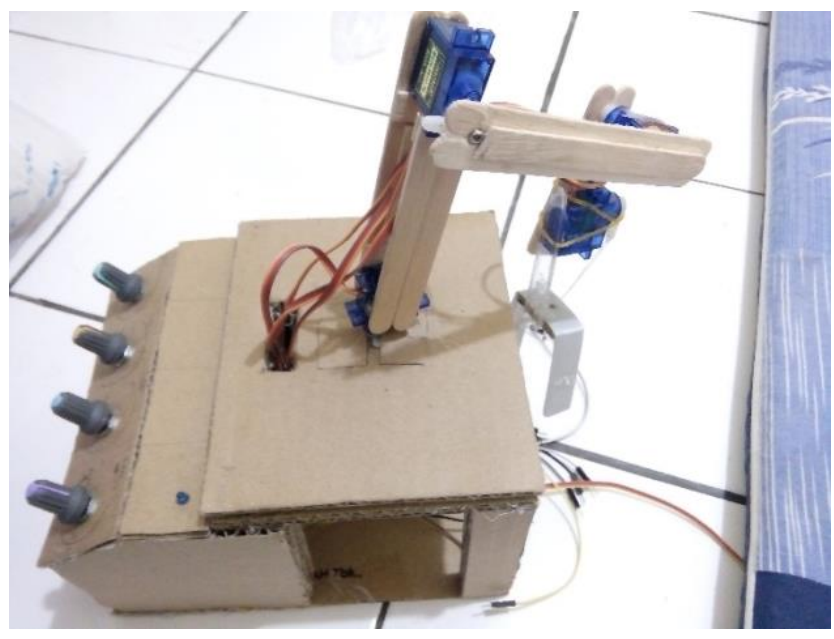

Figure 6. Robotic Arm Design

\section{Shoulder}

We use this part to rotate from left to right, so if the potentiometer rotates to left it would give 0 value for potentiometer and 0 value for servo. For the opposite direction it would give maximum values of each component and it would turn to right. Fig. 7 shows the shoulder part of the robotic arm.

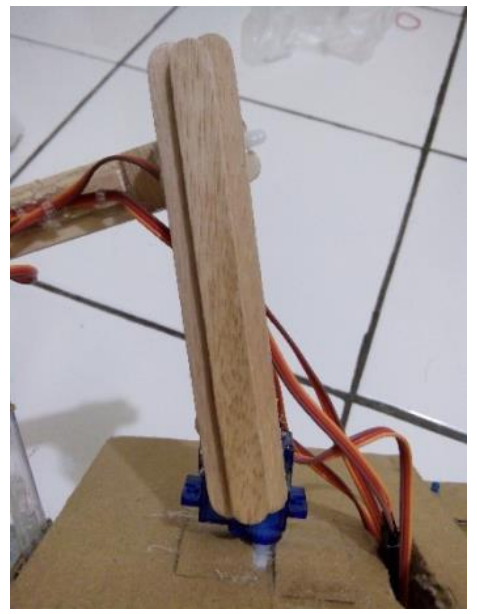

Figure 7. Shoulder

\section{Elbow}

We use this part to control up and down. If we rotate the potentiometer to the right it will rotate the elbow down. And if it is opposite direction it will rotate the elbow up. Fig. 8 shows the elbow part of the robotic arm.

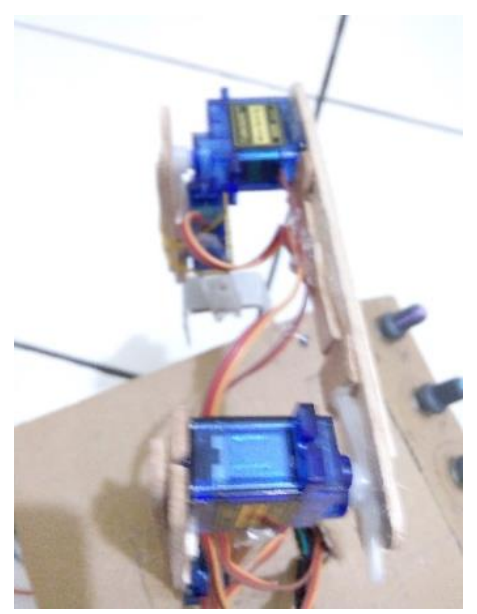

Figure 8. Elbow

\section{Wrist}

This part is controling the claw direction, far or near. If we rotate servo to the right the servo will go down which means far. This is shown in Fig. 9.

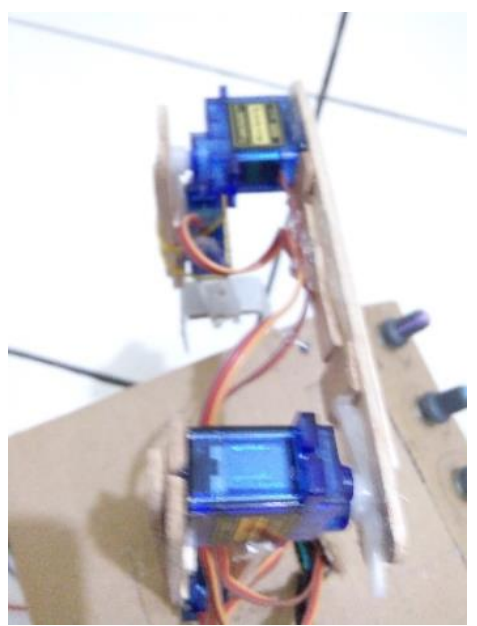

Figure 9. Wrist 


\section{Claw}

The lat servo motor is to grap the target. If potentiometer rotates to the right the claw is more tight. But if we rotate to the left it will release. Fig. 10 shows the claw part of the robotic arm.

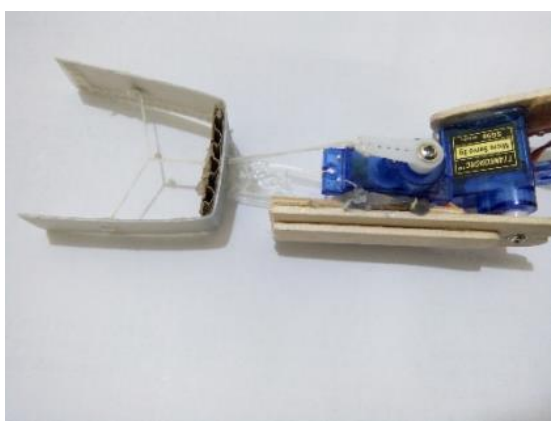

Figure 10. Claw

\section{Control Design}

Control of each servo joint is handled by potentiometer. These potentiometer works independent to each other. The construction of the controller is shown in Fig. 11.

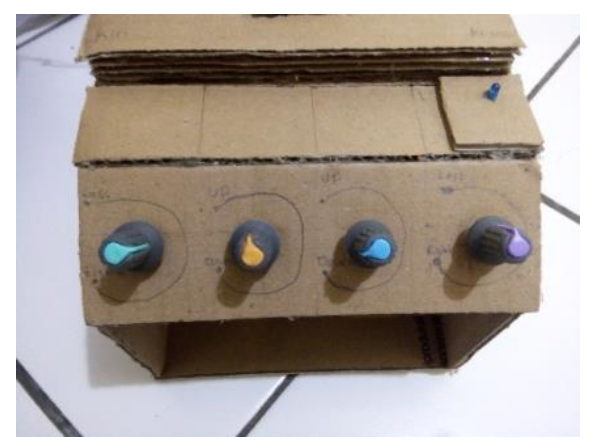

Figure 11. Potentiometer Controller

\section{CONCLUSION}

Robotic arm is one of the things needed to build a progress towards generation 4.0. robotic arm really helps us in many sectors, military sector, hospital sector, industrial sector and others. but to make this happen we must upgrade our project to be more useful. there are still many shortcomings in this project. for example, wood that is not sturdy, limited target distance and etc.

\section{REFERENCE}

[1] W. M. H. W. Kadir, R. E. Samin, B. S. K. Ibrahim, "Internet Controlled a Robotic Arm".

[2] R Krishna, G. S. Bala, S. S. Asc, B. B. P. Sarma, "Design and Implementation of a Robotic Arm Based on Haptic Technology", International Journal of Enginering Research, 2012.

[3] A. Baba, "Robotic Arm Control with Arduino," no. June, 2017, doi: 10.13140/RG.2.2.10227.53286

[4] Robotic Arm Using Arduino [Online]. Available: http://otomasi.sv.ugm.ac.id/

2018/12/25/robotic-arm-using-arduino-uno/.

[Accessed: November 27, 2018]

[5] Robotic Arm [Online]. Available: https://create.arduino.cc/ projecthub/msr048/robotic-arm-62c4c2. [Accessed: November 27, 2018] 